\title{
Studies on Polymers Having High Dielectric Constants. IX. Blend Polymers Consisting of Highly Conducting Monomeric- TCNQ Salts and Insulating Polymers ${ }^{\dagger}$
}

\author{
Shinobu IKeno,* Masaaki Yokoyama, and Hiroshi MikawA \\ Department of Applied Chemistry, Faculty of Engineering, \\ Osaka University, Suita, Osaka 565, Japan.
}

(Received August 7, 1978)

\begin{abstract}
Highly conductive $N$-methylquinolinium- and quinolinium-TCNQ (tetracyanoquinodimethane) complex salts were blended with insulating polymers such as polystyrene or polysulfone to obtain polymers with high dielectric constants even in high frequency regions. Owing to the high conductivity of the conductive phase, blend polymers containing $2.2-4.6 \mathrm{wt} \%$ of TCNQ salts exhibit high dielectric constants $\left(\varepsilon_{\mathrm{r}}, 20-100\right)$ up to $1 \mathrm{MHz}$ at room temperature. The relaxation frequencies of these blend polymers are thus higher, by $c a$. two orders of magnitude, than those of blend polymers with $N$-n-butylquinolinium-TCNQ complex salt with conductivities about $10^{-3}$ of the present TCNQ salts. The application of $c a .30 \mathrm{kV} / \mathrm{cm}$ of DC voltage to some of the virgin samples especially alters the resistivities of blend polymers having resistivities below $10^{11} \Omega \mathrm{cm}$; resistivities tend to increase for those polymers having lower TCNQ salt concentrations, and to decrease for polymers with higher TCNQ salt concentrations. This application of high DC voltage renders the blend polymers excellent dielectrics whose $\varepsilon_{\mathrm{r}}$ and $\tan \delta$ are $20-100$ and $10^{-2}-10^{-3}$ at low frequencies.

KEY WORDS Dielectric Constant / Dielectric Loss / Blend Polymer/TCNQ

Salt / Insulating Polymer / Conductivity / Heterogeneous Dielectrics / Interfacial Polarization /
\end{abstract}

In a previous paper, ${ }^{1}$ we reported a new approach for obtaining polymers having high dielectric constants with low dielectric loss tangents. This approach was based on interfacial polarization in polymer blend systems consisting of an insulating phase and finely dispersed conductive phases. Using this approach, we blended an electrically conductive monomeric-TCNQ (tetracyanoquinodimethane) salt, $N$ - $n$-butylquinolinium-TCNQ complex salt with insulating polymers such as polystyrene or polysulfone, and attained the dielectric constants $\left(\varepsilon_{\mathrm{r}} \sim 100\right)$ and relatively low dielectric loss tangents $(\tan \delta \sim 3 \%)$ at low frequencies for these blend polymers.

Following the above approach, this paper deals with the preparation of new blend polymers with higher $\varepsilon_{\mathrm{r}}$ and lower $\tan \delta$ and a discussion of their electrical properties. A description is given of an

\footnotetext{
$\dagger$ The preceding paper VIII, ref 1 .

* On leave of absence from Research Division, Matsushita Electric Works Co. Ltd., Kadoma, Osaka 571, Japan.
}

interesting phenomenon in which the electrical properties of certain blend polymers change by the application of high DC voltage.

\section{EXPERIMENTAL}

$N$-methylquinolinium- and quinolinium-TCNQ complex salts, abbreviated as MQ(C)-TCNQ and $\mathrm{HQ}(\mathrm{C})-\mathrm{TCNQ}$, respectively, were prepared according to the method in the literature. ${ }^{2}$ The specific resistivities from compressed powder measurements were $9 \Omega \mathrm{cm}$ for MQ(C)-TCNQ and $6 \Omega \mathrm{cm}$ for HQ(C)-TCNQ at room temperature. The preparation of blend polymers and measurement of electrical properties were carried out in a manner described previously. ${ }^{1}$

\section{RESULTS AND DISCUSSION}

In Table I are shown the composition and specific resistivities of the blend polymers at room temperature. These resistivities are dependent to some extent on the applied voltage, decreasing with an increase in voltage, especially for blend polymers having re- 
Table I. Compositions and specific resistivities $(\rho)$ of the blend polymers at room temperature

\begin{tabular}{|c|c|c|c|c|c|}
\hline \multirow{2}{*}{ Sample } & \multirow{2}{*}{$\begin{array}{l}\text { Insulating }^{a} \\
\text { polymer }\end{array}$} & \multicolumn{2}{|c|}{ Complex salt } & \multirow{2}{*}{$\rho(\mathrm{RT}), \Omega \mathrm{cm}^{\mathrm{d}}$} & \multirow{2}{*}{$\rho(\mathrm{RT}), \Omega \mathrm{cm}^{\mathrm{e}}$} \\
\hline & & Type $^{b}$ & Content, wt $\%{ }^{\mathrm{c}}$ & & \\
\hline I & $\mathrm{St}$ & M & 2.3 & $10^{8}$ & $10^{14}$ \\
\hline II & $\mathrm{St}$ & M & 4.6 & $10^{10}$ & $10^{14}$ \\
\hline III & St & M & 9.3 & $10^{5}$ & - \\
\hline IV & Sul & M & 2.3 & $>10^{16}$ & $10^{16}$ \\
\hline V & Sul & M & 4.6 & $>10^{15}$ & $10^{15}$ \\
\hline VI & Sul & M & 9.3 & $10^{9}$ & $10^{5}$ \\
\hline VII & St & $\mathrm{H}$ & 0.90 & $>10^{16}$ & $>10^{16}$ \\
\hline VIII & St & $\mathrm{H}$ & 2.2 & $10^{10}$ & $10^{14}$ \\
\hline IX & St & $\mathrm{H}$ & 4.5 & $10^{10}$ & $10^{5}$ \\
\hline $\mathrm{X}$ & Sul & $\mathrm{H}$ & 0.90 & $>10^{16}$ & $10^{16}$ \\
\hline XI & Sul & $\mathrm{H}$ & 2.2 & $>10^{16}$ & $10^{16}$ \\
\hline XII & Sul & $\mathrm{H}$ & 4.5 & $10^{14}$ & $10^{12}$ \\
\hline
\end{tabular}

a St, polystyrene; Sul, polysulfone.

b $\mathrm{M}, N$-methylquinolinium-TCNQ complex salt; $\mathrm{H}$, quinolinium-TCNQ complex salt.

c The amount of complex salts is regulated so as to make the TCNQ content equal to that of the blend polymers with $\mathrm{BQ}(\mathrm{c})-\mathrm{TCNQ}$, reported previously.

d Values under low-field strength.

e Values following high-voltage treatment.

sistivities from $10^{7}$ to $10^{11} \Omega \mathrm{cm}$. These characteristics are similar to blend polymers with $N$ - $n$-butylquinolinium-TCNQ complex salt (BQ(C)-TCNQ) reported previously. ${ }^{1}$ On application of DC voltage, the current response of the blend polymers with resistivities below $10^{14} \Omega \mathrm{cm}$ was instantaneous and the current was constant with a slight noise in the low field strength, while the current decreased with time in the high field strength. Following application of $300-400 \mathrm{~V}$ (corresponding to a field strength of $c a$. $30 \mathrm{kV} / \mathrm{cm}$ ) for an appropriate time, the resistivities changed, especially for those polymers having resistivities below $10^{11} \Omega \mathrm{cm}$; with this treatment, resistivities tend to increase for polymers with lower TCNQ salt concentrations and decrease for polymers with higher TCNQ salt concentrations. Resistivity values following application of high voltage (high voltage treatment) are also listed in Table I. This change in resistivities by high voltage treatment is very interesting, and presumably related to changes in the contact between the conducting TCNQ salts dispersed in the insulating matrices; i.e., some of the conducting sequences of the TCNQ salts are broken in the polymers with lower TCNQ salt concentrations, resulting in high resistivities. In polymers with higher TCNQ salt concentrations, some of the TCNQ salts make contact with each

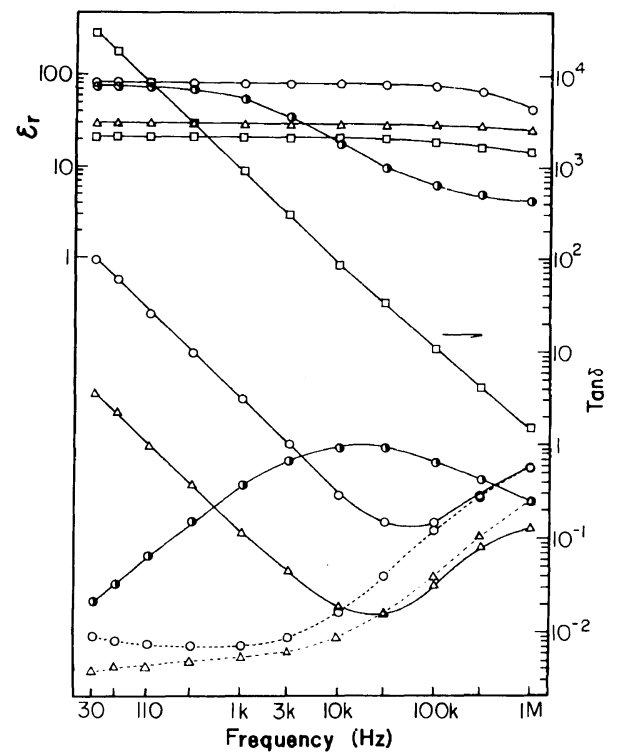

Figure 1. Plots of dielectric constants, $\varepsilon_{\mathrm{r}}$ and $\tan \delta v s$. frequencies for blend polymers consisting of $\mathrm{MQ}(\mathrm{C})-\mathrm{TCNQ}$ and polystyrene at room temperature: $\bigcirc$, sample I; $\triangle$, sample II; $\square$, sample III; $\bigcirc$, a blend polymer consisting of $\mathrm{BQ}(\mathrm{C})-\mathrm{TCNQ}(5.0 \mathrm{wt} \%)$ and polystyrene, cited from ref 1 for comparison. Dotted lines show values following high-voltage treatment. 


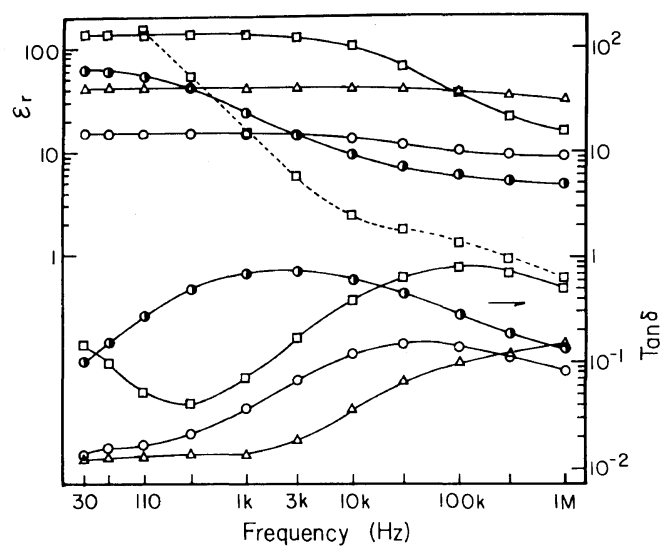

Figure 2. Plots of $\varepsilon_{\mathrm{r}}$ and $\tan \delta v s$. frequencies for blend polymers consisting of $\mathrm{MQ}(\mathrm{C})-\mathrm{TCNQ}$ and polysulfone at room temparature: $O$, sample IV; $\triangle$, sample $\mathrm{V} ; \square$, sample VI; $O$, a blend polymer consisting of $\mathrm{BQ}(\mathrm{C})-\mathrm{TCNQ}(5.0 \mathrm{wt} \%)$ and polysulfone, cited from ref 1 for comparison. Dotted lines show values following high-voltage treatment.

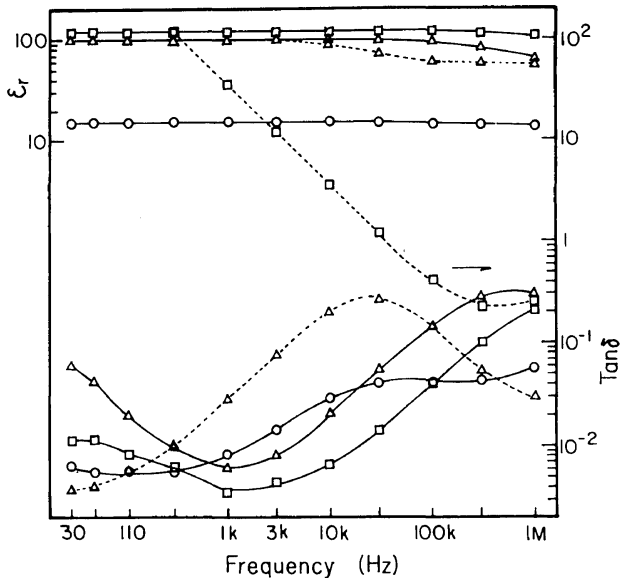

Figure 3. Plots of $\varepsilon_{\mathrm{r}}$ and $\tan \delta v s$. frequencies for blend polymers consisting of $\mathrm{HQ}(\mathrm{C})-\mathrm{TCNQ}$ and polystyrene at room temperature: $\bigcirc$, sample VII; $\triangle$, sample VIII; $\square$, sample IX. Dotted lines show values following highvoltage treatment.

other, thus forming contınuous sequences of TCNQ salts, resulting in low resistivities. These changes in the contact between microcrystals of TCNQ salts are presumably induced by the motion of TCNQ salts brought on by Joule's heat, locally evolved through conducting sequences of the salts. The appearance of the specimens does not change by the high voltage treatment except for sample VI, which apparently shows a few instances of change (may be melting) on

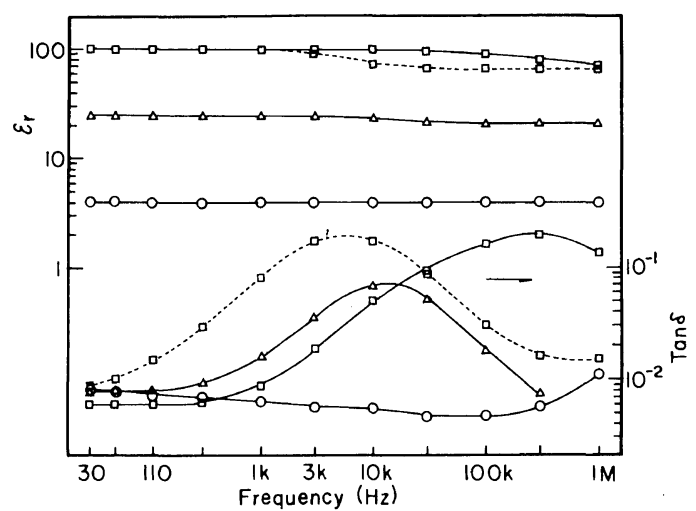

Figure 4. Plots of $\varepsilon_{\mathrm{r}}$ and $\tan \delta v s$. frequencies for blend polymers consisting of $\mathrm{HQ}(\mathrm{C})-\mathrm{TCNQ}$ and polysulfone at room temperature: $O$, sample $\mathrm{X} ; \triangle$, sample $\mathrm{XI} ; \square$, sample XII.

the film surface. As shown in Table I, the resistivity of the blend polymers following high voltage treatment decreases with an increase in the concentration of TCNQ salts. Considering the amount of the conductive phase composed of TCNQ salts, resistivities of the blend polymers following high voltage treatment are considered more reasonable.

Figures 1-4 show the frequency dependence of $\varepsilon_{\mathrm{r}}$ and $\tan \delta$ of blend polymers at room temperature. The dotted lines show typical data taken after application of high voltages and shorting for two days. As can be seen from the figures, the relaxation frequencies of the present blend polymers shift to higher frequencies, as compared with those of the blend polymers with $\mathrm{BQ}(\mathrm{C})-\mathrm{TCNQ}$ reported previously. ${ }^{1}$ Similar to the blend polymers with $\mathrm{BQ}(\mathrm{C})-\mathrm{TCNQ}$, relaxation frequencies $f_{\mathrm{m}}$ are higher for blend polymers in the polystyrene matrix than for blend polymers in the polysulfone matrix. According to the theory of heterogeneous dielectrics, ${ }^{3}$ higher conductivities of the conductive phases dispersed in an insulating matrix make the relaxation frequencies higher, leading to higher $\varepsilon_{\mathrm{r}}$ and lower $\tan \delta$ up to a high frequency region. The TCNQ salts used for blend in the present blend polymers such as MQ(C)-TCNQ and HQ(C)-TCNQ have higher conductivities by three orders of magnitude than $\mathrm{BQ}(\mathrm{C})-\mathrm{TCNQ}$ which was used for previous blend polymers. ${ }^{1}$ Therefore, these shifts of $f_{\mathrm{m}}$ to higher frequencies attained in the present blend polymers result from the higher conductivities of the TCNQ salts used for blend. 
The dielectric loss tangent of sample I decreased markedly in the low frequency region by the high voltage treatment. However, the dielectric constant and the relaxation frequency present in the over 1$\mathrm{MHz}$ region were maintained without change. This marked decrease of $\tan \delta$ is caused by the absence of any contribution of DC conduction to $\tan \delta$ values (as shown in Table I, the specific resistivity increases by four orders of magnitude by the high voltage treatment). It is well known that the DC conductivity $\sigma_{\mathrm{DC}}$ contributes to dielectric loss as exhibited by $\varepsilon^{\prime \prime}=\sigma_{\mathrm{DC}} /(2 \pi f)$, where $f$ is the frequency. Since $\varepsilon_{\mathrm{r}}$ of sample I is nearly constant below $30 \mathrm{kHz}$, if the contribution of DC conduction is predominant, the observed $\tan \delta$ should be proportional to $f^{-1}$. As can be seen from the figures, $\tan \delta$ of samples having rather high conductivities and of sample I prior to high voltage treatment exhibits $f^{-1}$ dependence in low frequencies. Therefore, the increase of $\tan \delta$ for these polymers in low frequencies can be attributed to DC conduction.

As shown in Figures 1-4, $\varepsilon_{\mathrm{r}}$ increases with an increase in TCNQ salts, except for the blend polymers of $\mathrm{MQ}(\mathrm{C})-\mathrm{TCNQ}$ and polystyrene. The values of $\varepsilon_{\mathrm{r}}$ and the frequency dependence of $\varepsilon_{\mathrm{r}}$ are unchanged by the high voltage treatment for blend polymers with $\mathrm{MQ}(\mathrm{C})-\mathrm{TCNQ}$. However, interestingly, $\varepsilon_{\mathrm{r}}$ of the blend polymers with $\mathrm{HQ}(\mathrm{C})-\mathrm{TCNQ}$ begins to decrease at $3-10 \mathrm{kHz}$ and hence, $\tan \delta$ maxima appear at $3-30 \mathrm{kHz}$ by the high voltage treatment. Thus, the frequency dependence of dielectric properties of the blend polymers following the high-voltage treatment differs in the high-frequency region depending on the species of TCNQ salts. Although the reason for this difference is not clear, the thermal stability of the TCNQ salts may have some connection with this. It has been reported that the thermal stability of $\mathrm{HQ}(\mathrm{C})-\mathrm{TCNQ}$ is inferior to that of MQ(C)-TCNQ. ${ }^{4}$ Thus, the conductivity of some of the conductive sequences of TCNQ salts contributing electric polarization is likely to decrease to some extent for the blend polymers with HQ(C)-TCNQ by the high-voltage treatment, resulting in a decrease of $\varepsilon_{\mathrm{r}}$ at $3 \mathrm{kHz}-1 \mathrm{MHz}$.

The blend polymer films are opaque to transparent depending on the content of complex salts. Figure 5 shows micrographs of blend polymers with low TCNQ concentrations. As can be seen from the micrographs, the TCNQ salts are dispersed microscopically in the insulating polymers as very fine (a)

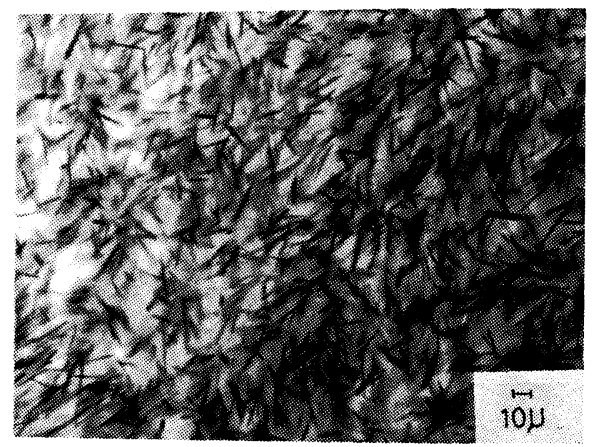

(b)

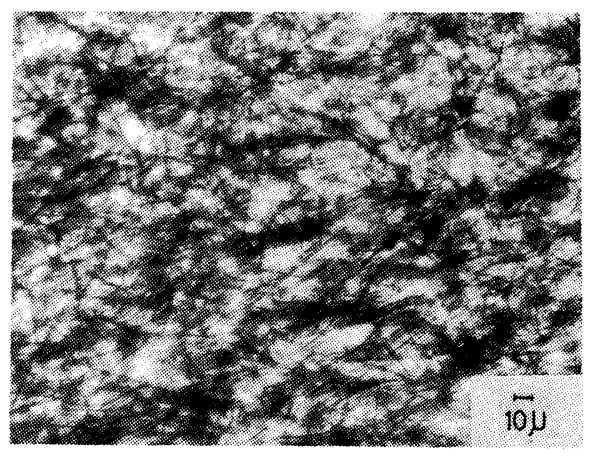

(c)

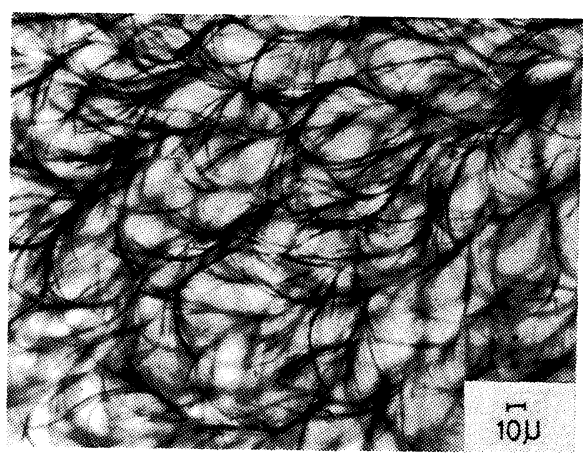

Figure 5. Micrographs of blend polymers: (a), blend polymer composed of $2.3 \mathrm{wt} \%$ of MQ(C)-TCNQ and polysulfone; (b), blend polymer composed of $2.2 \mathrm{wt} \%$ of $\mathrm{HQ}(\mathrm{C})-\mathrm{TCNQ}$ and polystyrene; (c), blend polymer composed of $2.5 \mathrm{wt} \%$ of $N-n$-butylquinolinium-TCNQ complex salt and polystyrene. The dielectric properties of this blend polymer have been reported in ref 1 .

needle- to thread-like crystals. As reported in the previous paper, ${ }^{1}$ these needle-like shapes of the conducting phases are responsible for the high $\varepsilon_{\mathrm{r}}$ attained in the present blend polymers. Among the blend polymers, the sample $\mathrm{X}$ is transparent, since the content of the complex salt in sample $\mathrm{X}$ is low and its matrix polymer, polysulfone, has rather good 
compatibility with the TCNQ salts. The complex salt in sample X may be dissolved more or less in the polysulfone, like a homogeneous solution. Thus, no distinct conductive phases may exist in this material and no interfacial polarization may be expected. For this reason, $\varepsilon_{\mathrm{r}}$ of sample $\mathrm{X}$ is lower than that of sample VII which has distinct conductive phases in the polystyrene matrix.

The above results show clearly that the complex salts having higher conductivities shift the relaxation frequencies to higher frequencies and at the same time, marked improvement in $\tan \delta$ is also attained. The selection of $N$-methylquinolinium- and quinolinium-TCNQ complex salts has proven good for this purpose. Sometimes the application of high voltage to the films improved the dielectric properties of the material appreciably. This interesting phenomenon induced by the high-voltage treatment should be clarified in the future. For further development of blend polymer systems with higher $\varepsilon_{\mathrm{r}}$ and lower $\tan \delta$, (1) the search for other conductive organics as a dispersed phase and (2) the study of the relation between electrical properties and the microstructure of blend polymers are very important.

Acknowledgement. Shinobu Ikeno, who is one of the authors of this paper is grateful to the Managing Director of the Matsushita Electric Works Co. Ltd., K. Kobayashi and the Manager of Chemical Products Section, T. Murakami for providing him with the opportunity of carrying out this work at Osaka University.

\section{REFERENCES}

1. S. Ikeno, M. Yokoyama, and H. Mikawa, Polym. J., 10, 231 (1978).

2. L. R. Melby, R. J. Harder, W. R. Hertler, W. Mahler, R. E. Benson, and W. E. Mochel, J. Am. Chem. Soc., 84, 3374 (1962).

3. R. W. Sillars, J.I.E.E., 80, 378 (1937).

4. Published unexamined patent application 50-135583 (1975). 